\title{
Zastosowanie metod instrumentalnych w badaniach meteorytu Morasko
}

\author{
Agata Duczmal-Czernikiewicz ${ }^{1}$, Andrzej Muszyński ${ }^{1}$, Tomasz Runka ${ }^{2}$, \\ Bożena Gołębiewska ${ }^{3}$, Danuta Michalska ${ }^{1}$, Lukasz Karwowski $^{4}$
}

\begin{abstract}
Application of instrumental methods in the Morasko Meteorite investigations. Prz. Geol., 67: 156-158; doi: 10.7306/2019.6
A b s tra c t. Since its discovery, the Morasko meteorite has been the subject of many studies. Among the publications summarising the mineralogical and geochemical characteristics of the Morasko meteorite, two monographs are worth mentioning by: Dominik (1976) and Muszyński et al. (2012), in which the essential features of the Morasko meteorite were presented. Since the first piece of the Morasko meteorite was to be explored, the analysis of mineral composition has been conducted with more and more specialised and sophisticated instrumental methods. As it is well known, the Morasko meteorite is classified into the group of iron meteorites IAB MG, and consists mainly of the crystalline Fe-Ni alloy in the form of two minerals: kamacite and taenite, accompanied by tetrataenite. A commonly found structure of the mineral composition of the Morasko meteorite, as regards other iron meteorites, are graphite-troilite nodules, which contain silicate and phosphate minerals. This paper presents a review of research on the mineralogy and geochemistry of the Morasko meteorite, where a number of instrumental tests have been used, from microscopic observations to microchemical semi-quantitative analyses using scanning electron microscopy (SEM-EDS), microchemical quantitative analyses using an electron microprobe (WDS), to the structural methods applying Raman spectroscopy. The results of microscopic, microchemical and microstructural investigations, which have included the outer layer of the meteorite known as a fusion crust, have been presented against the petrographic composition of the meteorite. Besides, the type of sediment attached to the outer meteorite layer was examined. The research, conducted on two dozen meteorite fragments, allowed distinguishing two different zones concerning mineralogy and geochemistry, and to determine microstructural changes within them, most probably created in the processes related to the moment of the meteorite impact.
\end{abstract}

Keywords: Meteorite Morasko, mineralogy, SEM-EDS, WDS, Raman spectroscopy

Metody instrumentalne stosowane do rozpoznania składników mineralogicznych i geochemii obejmują zespół metod badawczych począwszy od tradycyjnej mikroskopii kruszcowej przez badania mikrochemiczne metodami w mikroobszarze. Meteoryt Morasko był przedmiotem badań mineralogicznych w odniesieniu do faz tworzących wnętrze metaliczne, nodul grafitowo-troilitowych oraz zewnętrznej warstwy meteorytu, znanej w literaturze jako skorupa obtopieniowa (ang. fusion crust). Przedmiotem badań były ponadto osady z zewnętrznej warstwy skorupy obtopieniowej, przyłączone do meteorytu Morasko w momencie jego upadku. Podobnie jak inne meteoryty żelazne jest zbudowany z faz żelazo-niklowych i należy do grupy meteorytów oktaedrycznych IAB MG (Pilski i in., 2013).

Meteoryt Morasko jest zbudowany ze stopu Fe-Ni, który tworzy minerały typowe dla meteorytów żelaznych struktury Widmastaettena, złożone z kamacytu i taenitu, podrzędnie tetrataenitu (Dominik, 1976; Muszyński i in., 2012). Wnętrze meteorytu odznacza się występowaniem grafitowych i grafitowo-troilitowych nodul, które zawierają także składniki krzemianowe (oliwiny, kwarc, skalenie, pirokseny), jak również minerały z grupy fosforanów, i obecnością schreibersytu (Muszyński i in., 2012). W nodulach za pomoca mikroskopii skaningowej były badane główne ich składniki grafit i troilit (ryc. 1 - patrz str. 208), ale również inne, takie jak krzemiany (oliwiny, pirokseny, skalenie), tellurki (ryc. 2 i 3) i fosforany, wśród których odkryto niedawno dwa nowe minerały: moraskoit i czochralskiit (Karwowski i in., 2015). Powierzchnia meteorytu

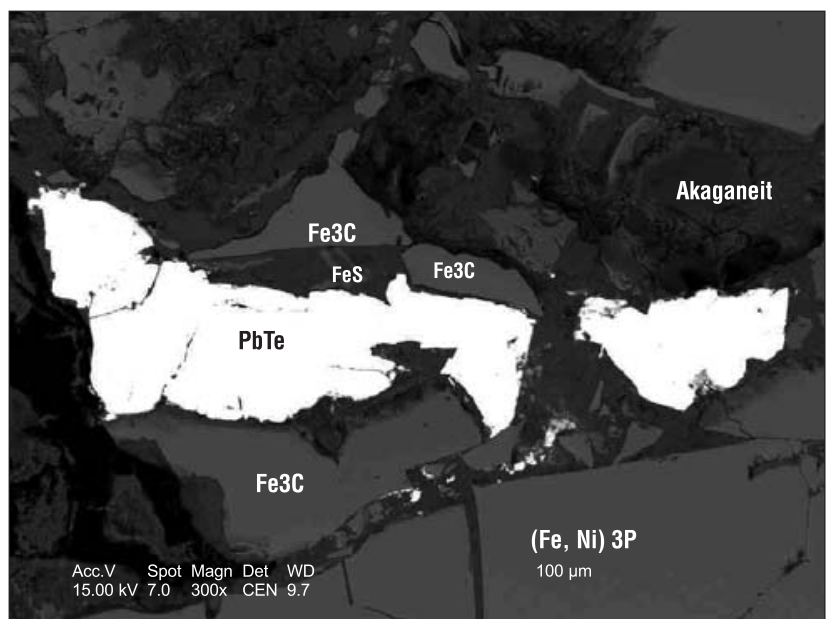

Ryc. 2. Ałtait $(\mathrm{PbTe})$ w otoczeniu cohenitu $\left(\mathrm{Fe}_{3} \mathrm{C}\right)$ oraz akaganeitu $(\beta-\mathrm{FeO}(\mathrm{OH}))$. Obraz w elektronach wstecznych $\mathrm{z}$ mikrosondy elektronowej

Fig. 2. Attaite: $\mathrm{PbTe}$ in cohenite: $\mathrm{Fe}_{3} \mathrm{C}$ and akaganeite: $\beta-\mathrm{FeO}(\mathrm{OH})$ surroundings. BSE-WDS image

jest pokryta charakterystycznymi wgłębieniami, które tworzą struktury z wytopienia, tzw. regmaglipty, związane z przelotem ciała podczas wędrówki przez atmosferę ziemską.

Metamorfizm zderzeniowy (uderzeniowy, impakcyjny, szokowy) to rodzaj metamorfizmu, który jest wywołany uderzeniem meteorytu, przy czym im uderzenie wywołane jest większym ciałem i zachodzi z wiekszą prędkością, tym

\footnotetext{
${ }^{1}$ Instytut Geologii, Uniwersytet im. Adama Mickiewicza w Poznaniu, ul. Bogumiła Krygowskiego 12, 61-680 Poznań; duczer@amu.edu.pl

${ }^{2}$ Instytut Badań Materiałowych i inżynierii Kwantowej, Politechnika Poznańska, ul. Piotrowo 2, 61-138 Poznań

3 AGH Akademia Górniczo-Hutnicza, Katedra Mineralogii, Geochemii Petrografii i Geochemii, al. Mickiewicza 30, 30-059 Kraków

${ }^{4}$ Katedra Geochemii, Mineralogii i Petrografii, Uniwersytet Śląski, ul. Będzińska 60, 41-205 Sosnowiec
} 


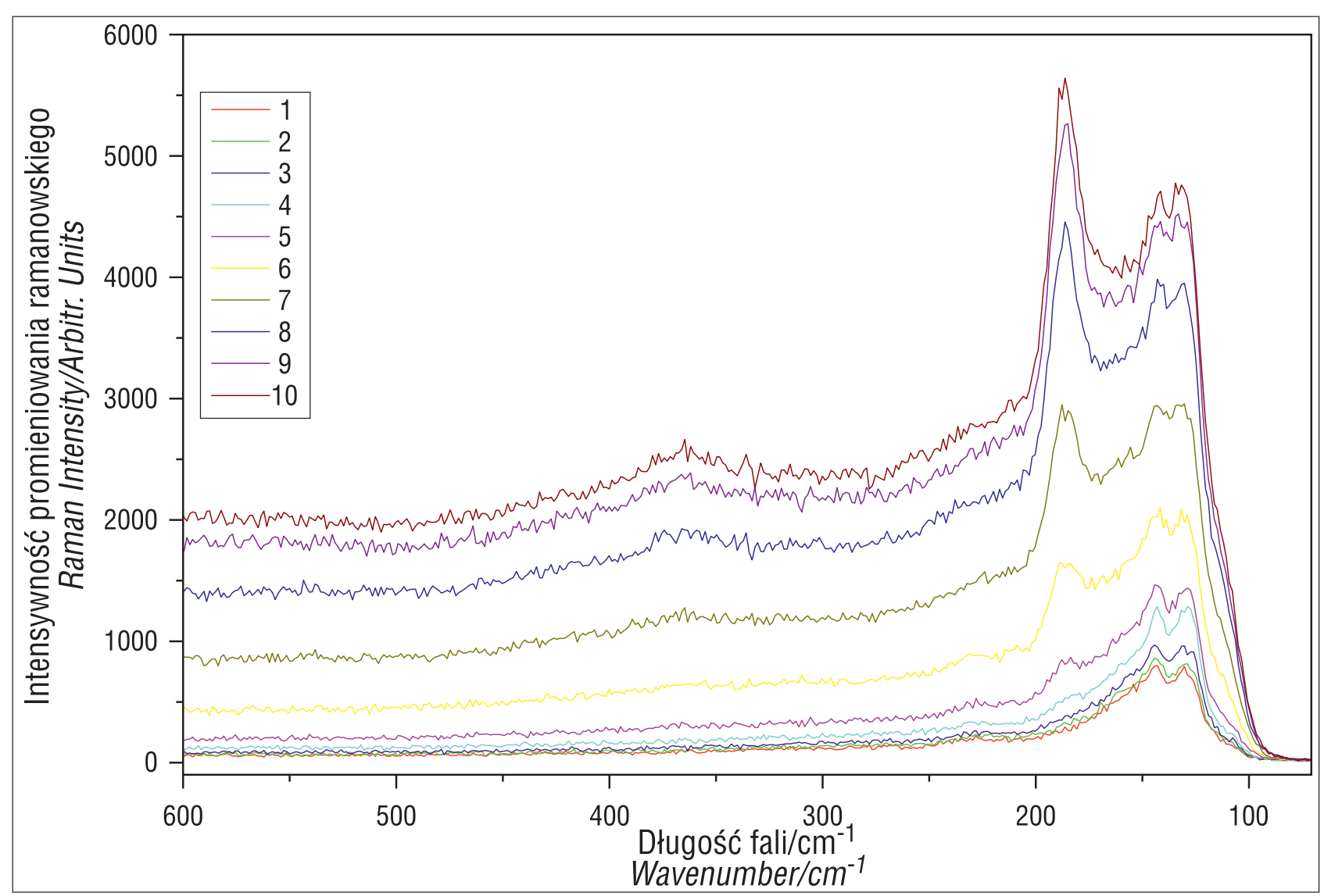

Ryc. 3. Widma ramanowskie ałtaitu przy różnych warunkach analitycznych (1-10), Mikroskopia Ramana

Fig. 3. Microraman spectra of altaite crystal under diverse analytical conditions (1-10), data from Raman Spectroscopy

efekty są intensywniejsze. Przeobrażenia zachodzą pod wpływem fali zderzeniowej w bardzo krótkim czasie, ale w przypadku dużych meteorytów czas wzrasta nawet do jednej minuty (Melosh, 1989; Grieve i in., 1996). Ciśnienie wynosi nawet do $100 \mathrm{GPa}$, a temperatura może dochodzić do $5000^{\circ} \mathrm{C}$ (French, 1998). Zmiany minerałów przez działanie silnych fal szokowych obejmują deformacje, transformacje, dekompozycję i topienie, a na ostatnim etapie odparowywanie. Efekty impaktu (szoku) są aktywowane przez ciśnienie i temperaturę, a ich działanie jest zależne od struktury kryształu oraz składu chemicznego minerału. Zmiany struktur minerałów z otoczenia meteorytu Morasko wywołane szokiem impaktowym były badane metodami mikroskopowymi (SEM-EDS), mikrochemicznie (WDS) oraz przy użyciu spektroskopii ramanowskiej,

\section{MATERIAŁ BADAWCZY I METODYKA}

Przedmiotem badań było 11 fragmentów meteorytów wypolerowanych, wytrawionych i pociętych na szlify petrograficzne uniwersalne (4) oraz zgłady (7). Płytki cienkie polerowane oraz zgłady poddano obserwacjom w mikroskopie kruszcowym (Zeiss, Axioplan - Instytut Geologii UAM; SEM-EDS - WNGiG Poznań), a także mikrosondzie elektronowej WDS (CAMECA - Uniwersytet Warszawski). Badania ramanowskie wybranych próbek wykonano na Politechnice Poznańskiej oraz w Katedrze Mineralogii Geochemii i Geologii Środowiskowej na Akademii Górniczo-Hutniczej.

\section{WYNIKI}

Większość składników szkieletu ziarnowego skorupy z zewnętrznych stref badanych okruchów meteorytów (ponad 90\%) stanowią ziarna kwarcu. Rozmiary tych ziaren zmieniają się od $0,2 \mathrm{~mm}$ do $0,5 \mathrm{~cm}$. Przeważnie są one wykształcone w formie monokryształów, ale także polikrystalicznych zrostów. Wykazują one bardzo silne pokruszenie, spękanie, często występują także ziarna z inkluzjami mineralnymi i gazowo-mineralnymi. Spękania są rozmieszczone nierównomiernie, większe i bardziej widoczne są rozwinięte wzdłuż granic ziaren. Występują w wielu przypadkach w grupach i są one przeważnie równoległe do powierzchni meteorytu. Pokruszone fragmenty kwarcu są często przemieszczone względem ziarna macierzystego. Skalenie niejednokrotnie zawierają spękania i szczeliny, które wykazują schodkowany przebieg i obejmują zarówno ziarna szkieletu ziarnowego, jak i masę wypełniającą; czasami skalenie są zastępowane przez minerały wtórne.

Ziarna szkieletu ziarnowego wykazują różnorodny stopień zniszczenia. W ich obrębie występują mikrokratery. Struktury typu mikrokraterów, które występują w regolicie obejmują ziarna kwarcu, które są rozerwane lub/i częściowo popękane i pokruszone. Mikrokratery mają kształt litery $\mathrm{U}$ lub $\mathrm{V}$ i są skierowane (otwarte) przeważnie w stronę meteorytu.

W najliczniejszej grupie składników szkieletu ziarnowego: kwarcu i skaleni, są widoczne liczne spękania oraz szczeliny o przebiegu zygzakowatym, przy czym spękania te są często usytuowane wzdłuż krawędzi meteorytu 
(ryc. 4 - patrz str. 208). Ziarna kwarcu miejscami występują w formie uporządkowanej, tworząc teksturę kierunkową. Nieliczne żyłki i szczeliny w kwarcu są najczęściej wypełnione geothytem lub kalcytem. Żyłki znajdują się w całym osadzie, ale także w zwietrzałej części meteorytu. Miejscami żyłki są wypełnione węglanem wapnia, który, jak wykazano w badaniach SEM, odznacza się podwyższoną zawartością magnezu. Mikryt węglanowy tworzy masę wypełniającą (matriks) wraz z minerałami ilastymi dla szkieletu ziarnowego w jednym badanym fragmencie meteorytu.

W badaniach mikroskopowych stwierdzono charakterystyczne efekty metamorfizmu szokowego takie jak: deformacje i pokruszenie kryształów kwarcu, skaleni oraz ślady dekompozycji minerałów. W dotychczasowych badaniach ramanowskich nie stwierdzono jednak typowych struktur szokowych, opisywanych jako struktury planarne (ang. planar deformation structures).

\section{DYSKUSJA}

Efekty istnienia metamorfizmu szokowego w minerałach pozwalają na zgrubne oszacowanie wielkości ciśnienia szokowego (Stöffler, Langenhorst, 1994). Im większe jest ciśnienie (oraz temperatura), tym wyraźniejsze są efeky metamorfizmu szokowego (Langenhorst i in., 1992). W przypadku małych impaktów nie są one tak oczywiste, dlatego obecność opisanych wyżej tego typu deformacji świadczy o warunkach impaktowych. Mineralogia kruszcowa i skaningowa są stosowane w badaniach mineralogicznych do wykonywania analiz cech optycznych minerałów nieprzezroczystych, obserwacji morfologii ziaren oraz identyfikacji faz mineralnych w mikroobszarze przy użyciu analizy chemicznej. W świetle odbitym dobrze rozpoznawalne są również minerały przezroczyste lub przeświecające, w tym minerały skałotwórcze. Zastosowanie urządzeń SEM-EDS, WDS oraz spektroskopii ramanowskiej pozwoliły na określenie składu mineralnego meteorytu oraz opis zmian teksturalnych jego krawędzi i składników osadów wywołanych impaktem.

Zmiany optyczne i chemiczne są wywołane głównie wzrostem temperatury. Na podstawie ziaren kwarcu, od strony krawędzi meteorytu najbardziej zdeformowanego, można stwierdzić, że w podwyższonej temperaturze zachodziły przeobrażania, które deformowały w sposób niejednorodny i nierównomierny strukturę tego minerału. Izotropizacja obejmująca przeważnie tylko część pojedynczych ziaren kwarcu jest typową cechą wywołaną metamorfizmem szokowym (French, 1998). Izotropizacja ziarn kwarcu wraz ze strukturami planarnymi w skałach osadowych wokół wielkich kraterów była wielokrotnie opisywa- ne i stwierdzona eksperymentalnie (Grieve i in., 1996), jakkolwiek w małych kraterach występowanie tych cech optycznych jest dyskusyjne. Cechy optyczne i mikrostrukturalne kwarcu w strefie kontaktu meteorytu Morasko, wywołane pradowdopodobnie spieczeniem, objawiają się występowaniem refleksów wewnętrznych nietypowych dla kwarcu, wskazują więc, że uderzenie meteorytu o powierzchnię Ziemi spowodowało zmiany nie tylko mechaniczne, ale także termiczne w obrębie składników szkieletu ziarnowego.

\section{PODSUMOWANIE}

1. W badaniach mikroskopowych stwierdzono charakterystyczne efekty metamorfizmu szokowego, przede wszystkim deformacje i pokruszenie kryształów kwarcu, skaleni oraz ślady dekompozycji minerałów.

2. Ziarna szkieletu ziarnowego wykazują różnorodny stopień zniszczenia. Występują w nich mikrokratery i szczeliny wypełnione kalcytem oraz wtórnym geothytem.

3. Metody mikroskopowe (tradycyjna petrografia kruszcowa i mikroskopia skaningowa) w połączeniu $\mathrm{z}$ analizą w mikroobszarze (mikrosonda elektronowa, przystawka EDS do mikroskopu SEM) oraz badaniami ramanowskimi w mikroobszarze pozwoliły na szczegółową charakterystykę mineralogiczno-geochemiczną zarówno fragmentów meteorytu Morasko, jak i skorupy obtopieniowej rozwiniętej na tych fragmentach, oraz osadów z otoczenia tej skorupy.

4. Wyróżnione strefy różnią się od siebie zarówno ze względu na skład mineralny, jak i chemiczny.

\section{LITERATURA}

DOMINIK B. 1976 - Mineralogical and chemical study of coarse octahedrite Morasko. Pr. Mineral. PAN, 47: 7-53.

FRENCH B.M. 1998 - Traces of catastrophe: A handbook of shock-metamorphic effects in terrestrial meteorite impact structures. LPI Contribution 954. Houston, Texas: Lunar and Planetary Institute.

GRIEVE R.A.F., LANGENHORST F., STÖFFLER D. 1996 - Shock metamorphism of quartz in nature and experiment: II. Significance in geoscience. Meteoritic. Planet. Sci., 31: 6-35.

KARWOWSKI Ł., KUSZ J., MUSZYŃSKI A., SITARZ M., KRYZA R., GALUSKIN E. 2015: Moraskoite $\mathrm{Na}_{2} \mathrm{Mg}\left(\mathrm{PO}_{4}\right) \mathrm{F}$ (Poland). Mineral. Mag., 79 (2): 387-398.

LANGENHORST F., DEUTSCH A., STÖFFLER D., HORNEMANN U. 1992 - Effect of temperature on shock metamorphism of single-crystal quartz. Nature, 356: 507-509.

MELOSH H.J. 1989 - Impact Cratering. A Geologic Process. Oxford Monographs on Geology and Geophysics Series, 11

MUSZYNSKI A. KRYZA R, KARWOWSKI Ł., PILSKI, A.S, MUSZYŃSKA J. 2012 - Morasko - the largest iron meteorite shower in Central Europe. Studia i Prace z Geografii i Geologii, 28. Bogucki Wyd. Nauk., Poznań.

PILSKI A.S. KRYZA R., WASSON J.T., MUSZYŃSKI A., KARWOWSKI Ł. 2013 - Low Ir-IAB-irons from Morasko and other location in central Europe. Meteor. Planet. Sci., 48: 2531-2541.

STÖFFLER D., LANGENHORST F. 1994 - Shock metamorphism of quartz in nature and experiment: I. Basic observation and theory. Meteoritic. Planet. Sci., 29: 155-181. 


\section{Zastosowanie metod instrumentalnych w badaniach meteorytu Morasko (patrz str. 156)}

Application of instrumental methods in the Morasko Meteorite investigations (see p. 156)

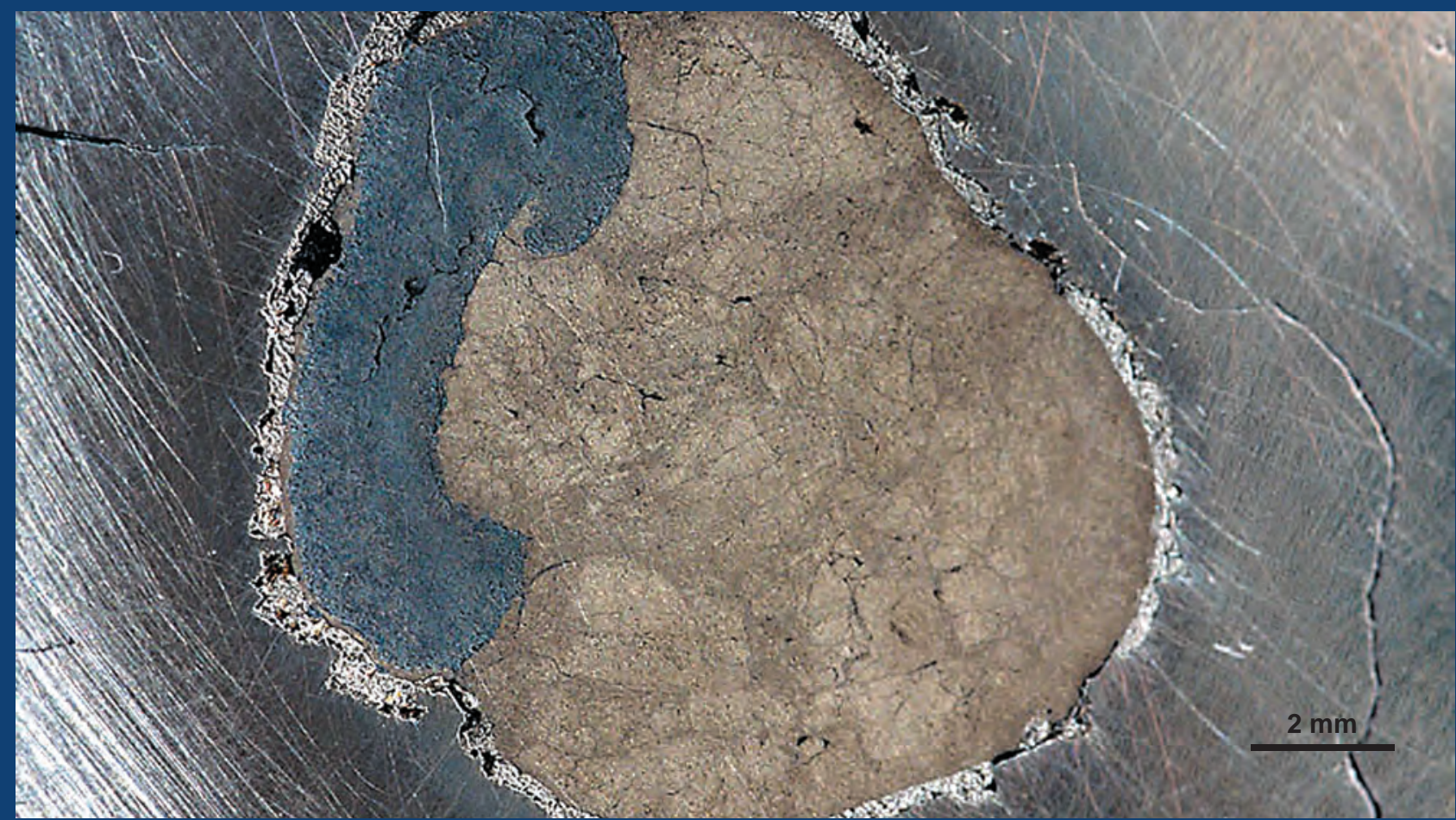

Ryc. 1. Meteoryt Morasko, powierzchnia polerowana, fotografia wykonana przy użyciu lupy binokularnej. Nodula troilitowo-grafitowa z otoczką schreibersytu w kamacycie; dłuższa krawędź zdjęcia - $2 \mathrm{~cm}$

Fig. 1. Morasko meteorite, polished surface, microphotography made using a binocular microscope. The troilite (metallic yellow) and graphite (black) nodule with a schreibersite rim, within the kamacite (silvery); the longer side of the photo $-2 \mathrm{~cm}$

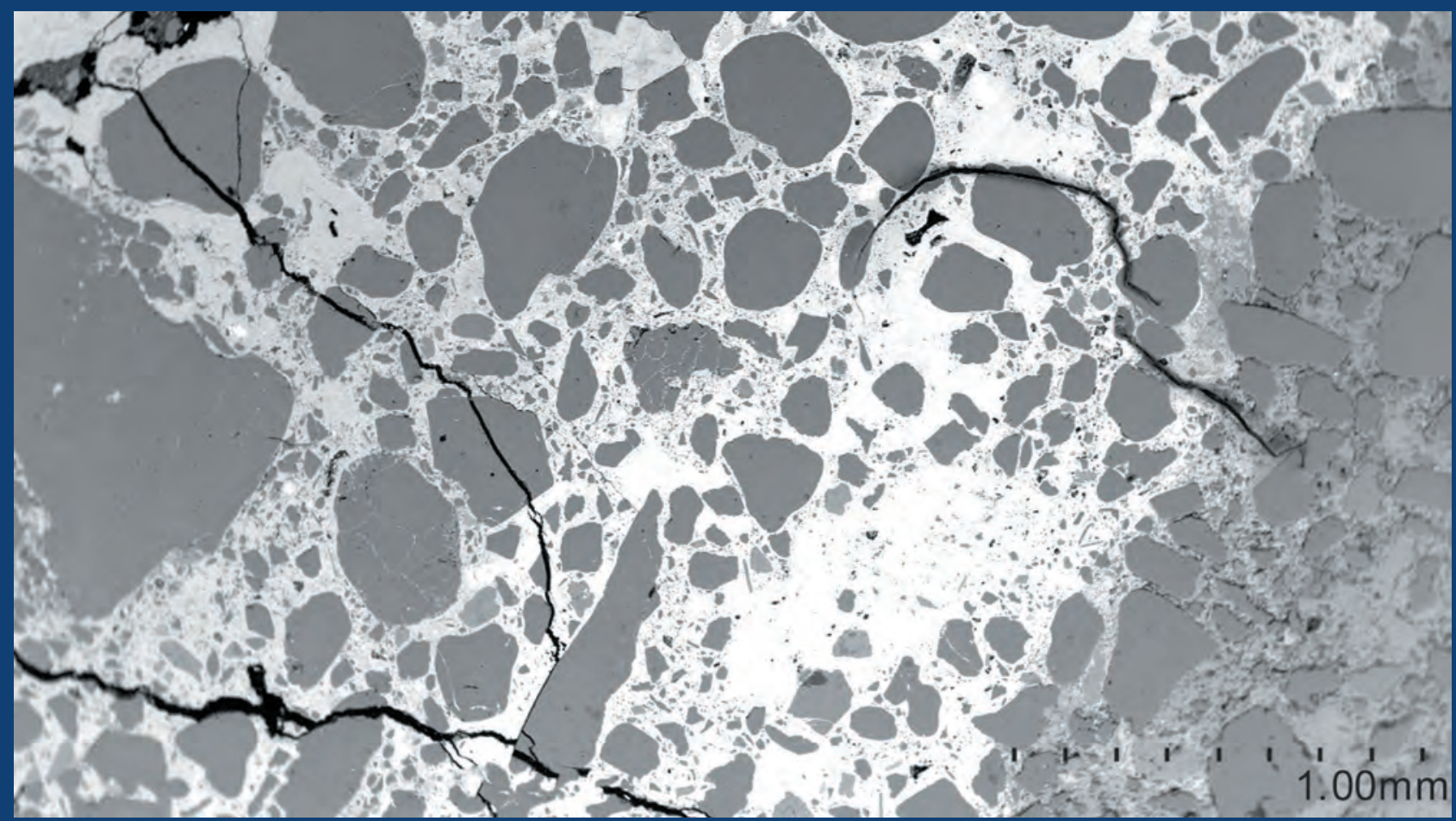

Ryc. 4. Osady z zewnętrznej skorupy fragment meteorytu, złożone z ziaren kwarcu i skaleni spojonych getytem, w dole fotografii widoczne żyłki wypełnione geothytem. Obraz w elektronach wstecznych z mikroskopu skaningowego

Fig. 4. Sediments from the outer crust of the meteorite specimen, composed of quartz (black) and feldspar (gray) grains, cemented by goethite, at the bottom of microphotography veins filled with goethite are visible. BSE-SEM image 